MEDIALOG: Jurnal IImu Komunikasi, Volume III, No. I, Februari 2020, hlm 147-158

\title{
STRATEGI KOMUNIKASI PEMASARAN TERPADU PROGRAM TALK SHOW HITAM PUTIH DI TRANS 7
}

\author{
Siti Asiatun ${ }^{1}$ \\ ${ }^{1}$ Program Studi Manajemen Multimedia, Sekolah Tinggi Multi Media Yogyakarta \\ Email: sasiatun@yahoo.co.id
}

\begin{abstract}
ABSTRAK
Tayangan talk show Hitam Putih menjadi salah satu program tayangan favorit penonton Indonesia. Kesuksesan program acara ini tidak luput dari strategi pemasaran yang dilakukan oleh tim talk show Hitam Putih.. Dalam ilmu komunikasi dikenal sejumlah saluran komunikasi, yaitu bagaimana cara orang berkomunikasi menyampaikan pesan kepada orang lain, baik komunikasi dengan tanpa media atau komunikasi dengan media.Penelitian ini bertujuan untuk mengetahui strategi komunikasi pemasaran terpaduprogram talk show Hitam Putih di Trans7 sehingga mampu bertahan sampai dengan sekarang. Metode penelitian yang digunakan adalah diskriptif kualitatif, menggunakan beberapa nara sumber narasumber utama yaitu Mayang Widi Anjani, Marketing Division Head Trans7 dan Suci Mulya Putri,Public Relations Section Head primer dan sumber sekunder berupa buku- buku, internet dan penayangan Talk Show"Hitam Putih sendiri.Hasil yang diperoleh dalam penelitian ini menerangkan mengenai Startegi komunikasi terpadu program Talk Show Hitam Putih di Trans 7 antara lain Pemasaran Langsung, Promosi Penjualan, Penjualan Pribadi, Membangun hubungan baik, Periklanan, dan Pemasaran Media Online. Talk show Hitam Putih di Trans7 dapat memasarkan program acaranya secara lebih luas dengan menerapkan strategi komunikasi pemasaran terpadu lain, misalnya dengan melakukan iklan kerja sama.
\end{abstract}

Kata Kunci: Strategi Komunikasi , Pemasaran Terpadu, Talk Show

\section{INTEGRATED MARKETING COMMUNICATION STRATEGY OF BLACK WHITE BLACK TALK SHOW PROGRAM ON TRANS 7}

\begin{abstract}
The Black and White talk show was one of the favorite programs of the Indonesian audience. The success of this program does not escape the marketing strategy carried out by the Black and White talk show team. In communication science there are a number of communication channels known, namely how people communicate to convey messages to others, both communication with no media or communication with the media. This research aims to find out the marketing communication strategy of the program Black and White talk show in Trans 7 so that it can survive until now, the research method used is descriptive qualitative, using several key informants namely Mayang Widi Anjani, Trans7 Marketing Division Head and Suci Mulya Putri, Public Relations Primary and secondary sources Section Head in the form of books, the internet and the airing of the Black and White Talk Show itself. The results obtained in this study describe the integrated communication strategy of the Black and White Talk Show program in Trans 7, including Direct Marketing, Sales Promotion, Sales Personal lan, Building good relations, Advertising, and Online Media Marketing. The Black and White talk show on Trans 7 can market its program more widely by implementing other integrated marketing communication strategies, for example by conducting joint advertisements
\end{abstract}

Keywords: Communication strategy, integrated marketing, Talk Show 
Korespondensi: Dra. Siti Asiatun., M.M. Program Studi Manajemen Multimedia, Sekolah Tinggi Multi Media Yogyakarta. Jalan Magelang Km. 6 Yogyakarta 55284. Indonesia Tel: (+62274) 561531, 562513. Fax: (+62274)

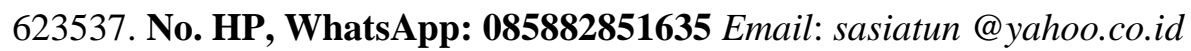

\section{PENDAHULUAN}

Menurut Ardiyanto (2009:6), komunikasi massamerupakansebuahproses dimana media memproduksi danmenyebarkan pesan kepada publik secara luas. Pesan yang disampaikan akan mencapai sasaran yang bersifat heterogen,tersebar, dan anonim. Pada media televisi, pesan akan diterima dalam waktu serentak.

Pada tanggal 16 Januari 2014 masyarakat Indonesia dihebohkan dengan adanya berita sebuah tayangan talk show yang dihentikan secara tiba-

tiba(www.id.wikipedia.org/wiki/Hitam_Putih_(ac ara_TV)).Masyarakat Indonesia yang kecewa karena keputusan tersebut, lalu beramai-ramai mengirim pesan dengan memakai tagar \#savehitamputih pada akun media sosial Komisi Penyiaran Indonesia (KPI) dan Trans7 tempat dimana program tersebut ditayangkan agar kembali mengudara. Karena banyaknya respon positif dari masyarakat dan penonton setianya, pada tanggal 03 Februari 2014 akhirnya talk show tersebut kembali tayang. Program talk show yang fenomenal ini adalah Hitam Putih yang dipandu oleh mantan mentalist terkenal Indonesia, yakni Deddy Corbuzier.

Program talk show Hitam Putih ditayangkan setiap hari Senin sampai dengan Jumat pada pukul 18.00 WIB di stasiun penyiaran Trans7 sebagai bagian dari kelompok media yang berada dalam naungan CT Corp. Saat ini Trans7 beroperasi berdasarkan Izin Penyelenggaraan Penyiaran Nomor 1820 Tahun 2016 tanggal 13 Oktober

2016 yang dikeluarkan oleh Kementerian

Komunikasi dan Informatika Republik Indonesia. Trans7 kini menjadi salah satu saluran televisi pilihan penonton Indonesia dengan positioning Smart, Entertaining \& Family (www.trans 7.co.id/programs/hitam-putih). Untuk itu program talk show Hitam Putih dibuat dengan tujuan memberi inspirasi sekaligus hiburan para penontonnya.

Program talk show Hitam Putih telah setia menemani penontonnya sejak tahun 2011 sampai sekarang (2019-red) atau terhitung 8 tahun berjalan. Hal ini membuktikan bahwa tayangan talk show Hitam Putih menjadi salah satu program tayangan favorit penonton Indonesia. Kesuksesan program acara ini tidak luput dari strategi pemasaran yang dilakukan oleh tim talk show Hitam Putih.

Persaingan media penyiaran pada dasarnya adalah persaingan merebut penonton dan untuk dapat merebut perhatian penonton, maka pengelola stasiun penyiaran harus memahami siapa penonton mereka dan apa kebutuhan mereka (Morissan, 2009:165). Guna dapat merebut perhatian penonton, maka dibutuhkan strategi marketing yang tepat sasaran dan efisien. Salah satu strategi dalam penyiaran yang banyak digunakan adalah komunikasi pemasaran terpadu atau sering disebut ingrated marketing communication (IMC).

Komunikasi pemasaran terpadumemakai strategi menggabungkan berbagai aktivitas pemasaran secara bersamaan, yaitu pemasaran 
langsung (direct marketing), promosi penjualan (sales promotion), hubungan masyarakat (public relations), penjualan personal (personal selling), periklanan (advertising).Kelima strategi diatas bila dijalankan dengan efektif dan terhubung dengan baik guna mencapai tujuan yang sama akan menjadi sebuah langkah penentu kesuksesan sebuah program acara televisi. Bagaimana talk show Hitam Putih menentukan strategi pemasaran programnya menjadi permasalahan yang menarik untuk dibahas, khususnya melalui cara komunikasi pemasaran terpadu.

\section{Strategi Komunikasi Pemasaran}

Menurut Kamus Besar Bahasa Indonesia, strategi adalah suatu rencana yang cermat mengenai suatu kegiatan untuk mencapai sasaran khusus (Departemen P dan K, 1989:859). Artinya, sebelum melakukan suatu kegiatan perlu dilakukan susunan rencana agar kelak pelaksanaannya berjalan sesuai rencana dan sesuai dengan tujuan yang ingin dicapai. Sedangkan pemasaran adalah proses pendistribusian produk dari produsen kepada konsumen dengan jalur yang se-efektif mungkin (Departemen $\mathrm{P}$ dan $\mathrm{K}$, 1989:719). Penyebutan produk dan konsumen disesuaikan dengan bidang pemasaran yang akan dituju.

Guna mencapai tujuan dari dibentuknya strategi pemasaran maka membutuhkan ilmu komunikasi yang terencana agar pesan yang ingin disampaikan kepada calon konsumen dapat diterima dengan baik dan mudah, sehingga nantinya akan timbul respon timbal balik. Dalam ilmu komunikasi dikenal sejumlah saluran komunikasi, yaitu bagaimana cara orang berkomunikasi menyampaikan pesan kepada orang lain, baik komunikasi dengan tanpa media atau komunikasi dengan media (Morissan, 2009:12). Komunikasi tanpa media atau antar pribadi dirasa kurang efektif dalam menyampaikan sebuah pesan karena bersifat privat, hanya diantara orang-orang yang saling bertatap muka secara langsung. Berbeda dengan komunikasi dengan media, sifat media yang dapat didengar dan dilihat secara publik tanpa harus bertatapmuka memungkinkan pesan yang disampaikan akan langsung diterima oleh banyak orang dalam satu waktu yang sama.

Komunikasi dengan media dibagi menjadi komunikasi lewat non-media massa dan media massa. Komunikasi lewat non-media massa memakai jasa manusia sebagai kurir dan benda, seperti telepon selular untuk menyampaikan pesan. Sedangkan komunikasi dengan media massa memakaimedia televisi, radio, maupun media cetak. Diantara ketiga media massa tersebut, komunikasi lewat televisi merupakan salah satu cara efektif dalam menyampaikan sebuah pesan. Menurut Fred Wibowo (2007:17), unsur essensial dari kebudayaan televisi berupa penggunaan bahasa verbal dan visual sekaligus dalam rangka menyampaikan sesuatu seperti pesan, informasi, pengajaran, ilmu, dan hiburan. Hal ini berarti kegiatan menonton televisi mampunyai unsur essensi dalam menyampaikan pesan berupa informasi, pengajaran, ilmu sekaligus hiburan dalam bentuk suara dan gambar. Dalam dunia penyiaran, strategi pemasaran mencakup analisis dan strategi pemasaran program acara. Perencanaan program pada intinya 
memiliki tujuan untuk memproduksi sendiri atau membeli program yang akan ditawarkan kepada audiens, dalam dunia televisi audiens adalah penonton..

\section{Komunikasi Pemasaran Terpadu}

Menurut Keith J Tuckwell(dalam Kotler, 1997:228), komunikasipemasaran terpadu merupakan sebuah kordinasidari semua bentuk komunikasi pemasaran yangdilakukan melalui sebuah program terpadu gunamemaksimalkan dampak target pada khalayak. Kunci dari komunikasi pemasaran terpadu ialah efektifitas cara berkomunikasi kepada sasaran, sehingga diharapkan timbul rasa penasaran dan ketertarikan terhadap produk atau jasa yang ditawarkan.

Komunikasi pemasaranmerupakan bentuk komunikasi yang ditunjukan untuk memperkuat strategi pemasaran gunameraih segmentasi yang lebihluas. Kajian inijuga dapat sebagai sejumlah upaya untukmemperkuat loyalitaspelanggan terhadapproduk yaitu barang dan jasa yang dimilikiperusahaan ( Kennedy dan Soemanagara, 2006:4).

\section{Strategi komunikasi pemasaran} terpadumerupakan konsep perencanaan komunikasi pemasaran yang menyadari nilai tambah dari suatu rencana komprehensif yang mengevaluasi peran strategis dari berbagai disiplin komunikasi, misalnya komunikasi umum, tanggapan langsung, promosi penjualan dan hubungan masyarakat. Dengan kata lain, komunikasi pemasaran terpadumemakai strategi menggabungkan berbagai aktivitas pemasaran secara bersamaan, yaitu pemasaran langsung (direct marketing), promosi penjualan (sales promotion), hubungan masyarakat (public relations), penjualan personal (personal selling), periklanan (advertising).

a. Pemasaran Langsung (Direct marketing)

Pemasaran langsung adalah upaya perusahaan untuk berkomunikasi secara langsung dengan calon pelanggan sasaran dengan maksud untuk menimbulkan tanggapan dan/atau transaksi penjualan (Morissan, 2009:439). Tujuan dari komunikasi secara langsung bagi perusahaan ialah untuk berdialog pada konsumenyang spesifik atau pada calon konsumen yangmenjadi sasaran perusahaan (Jurnal penelitan Umaimah Wahid, 2018:168). Dialog atau komunikasi yang dilakukan kepada sasaran konsumen diharapkan akan menimbulkan respon berupa transaksi penjualan terhadap barang atau jasa yang ditawarkan. Melalui strategi komunikasi pemasaran langsung ini pula, perusahaan dapat mendengar, memberikan respon positif dan menindaklanjuti hasil dialog dengan konsumen.

\section{b. Promosi Penjualan (Sales Promotion)}

Merupakan kegiatan pemasaran yang memberikan nilai tambah atau insentif kepada tenaga penjualan, distributor dan konsumen yang diharapkan dapat meningkatkan penjualan (Morissan, 2010:25). Diharapkan dengan adanya intensif dapat merangsang reaksi langsung dari tenaga penjualan, konsumen dan distributor agar lebih banyak meningkatkan daya jual. Strategi komunikasi promosi penjualan ini berorientasi pada konsumen agar mengingat merek dari suatu perusahaan dan melakukan repeat order secara terus menerus.

c. Penjualan Pribadi (Personal Selling) 
Merupakan kegiatan penjualan suatu produk secara pribadi dari penjual kepada pembeli, baik secara tatap muka maupun menggunakan alat komunikasi seperti telepon. Melalui interaksi langsung seperti ini, maka pihak penjual dapat melihat dan mendengarkan tanggapan dari pembeli guna memodifikasi informasi yang disampaikan setelah menerima tanggapan dari calon pembeli (Morissan, 2010:34).

Perbedaan antara strategi komunikasi pemasaran langsung dengan penjualan personal adalah media yang digunakan. Berdialog secara langsung dengan konsumen dapat memudahkan perusahaan, melalui tenaga penjualan, melihat dan mendengarkan respon langsung dari konsumen. Respon yang diberikan oleh calon konsumen dapat langsung dimodifikasi secara lebih efektif dan menarik oleh tenaga penjualan sehingga kemungkinkan untuk terjadi transaksi penjualan lebih besar terjadi. Pada dunia penyiaran, strategi komunikasi ini memudahkan perusahaan untuk menyesuaikan pesan berdasarkan request khusus dengan calon pemasang iklan atau calon sponsor (Morissan, 2009:438).

\section{d. Hubungan Masyarakat (Public Relations)}

Menurut Tom Branan (1998:137), hubungan masyarakat bertujuan untuk membina hubungan baik dengan berbagai kelompok masyarakat yang berhubungan dengan perusahaan melalui publisitas yang mendukung, membina citra perusahaan yang baik dan menangani atau menangkal desas-desus, cerita, atau peristiwa yang dapat merugikan perusahaan. Peran public relations tidak dapat dianggap remeh karena berhubungan dengan pertahanan citra sebuah perusahaan dimata masyarakat.Hubungan masyarakat akan sangat erat kaitannya dengan tanggung jawab sosial perusahaan atau sering dikenal sebagai CSR (corporate social responsibility)..

\section{e. Periklanan atau Advertising}

Adalah segala bentuk penyajian dan promosi bukan pribadi mengenai gagasan, barang, atau jasa yang dibayar oleh sponsor tertentu (Kotler dan Armstrong: 1997:77).Periklananmerupakan bentuk persuasif dari teori komunikasi pemasaran terpadu $(I M C)$ guna menstimulasitanggapan positif dari target pasar lewat komunikasi massa, seperti media cetak, media elektronik, dan media lainnya (billboards, Internet, dan lain-lain).

\section{Format Program Talk Show}

Talk show atau gelar wicara adalah program yang menampilkan satu atau beberapa orang untuk membahas suatu topik atau tema tertentu yang dipandu oleh seorang pembawa acara (Morissan, 2013:212). Sifat dari program ini adalah memberikan informasi namun tidak harus segera ditayangkan atau termasuk dalam berita soft news. Selain talk show, berita soft news lainnya adalah current affair, magazine, dan dokumenter.

Program talk show atau program wicara di televisi meliputi banyak format, antara lain, voxpopdan wawancara (Wibowo, 2007:67). Vox-pop atau vox populi bila diterjemahkan dalam bahasa indonesia adalah suara masyarakat. Vox-pop bertujuan untuk mendengar dan menampilkan pendapat masyarakat luas mengenai suatu masalah agar penonton dapat mengonfrontir dengan pendapatnya sendiri. 


\section{METODE PENELITIAN}

\section{A. Jenis Penelitian}

Dalam penelitian ini, Teknik pengumpulan data yang digunakan Penulis adalah sebagai berikut :

\section{a. Data Primer}

Penulis menggunakan data primer dengan metode wawancara kepada narasumber yang yang terlibat dan mengetahui mengenai strategi komunikasi pemasaran terpadu program talk show Hitam Putih di Trans7. Wawancara adalah suatu cara pengumpulan data yang digunakan untuk memperoleh informasi langsung dari sumbernya (Kriyantono, 2007:96). Agar wawancara berjalan dengan baik dan lancar, Penulis akan dibantu dengan alat pedoman wawancara, yaitu daftar pertanyaan yang telah disiapkan sebelumnya. Tetapi Penulis tidak akan terpaku hanya pada daftar pertanyaan saja, Penulis akan mengikuti fleksibilitas responden dalam menjawab pertanyaan untuk memungkinkan berkembangnya pertanyaanpertanyaan lanjutan untuk lebih mendalami permasalahan yang ada dalam rumusan masalah.

\section{b. Data Sekunder}

Data sekunder dilakukan dengan cara mempelajari dan meneliti berbagai dokumen atau literatur yang berkaitan dengan tema penelitian. Penelusuran berbagai literatur dalam penelitian ini akan diperoleh dari buku-buku perpustakaan, makalah, karangan-karangan ilmiah, tesis, dan sumber-sumber tertulis baik tercetak maupun elektronik lain.

c.Metode Analisis Data

Penelitian ini memakai metode deskriptif analisis kualitatif. Menurut Sugiyono (2007:13) penelitian deskriptif yaitu penelitian yang dilakukan untuk mengetahui nilai variabel mandiri, baik satu variabel atau lebih (independen) tanpa membuat perbandingan, atau menghubungkan dengan variabel yang lain.

Data yang diperoleh berdasarkan data primer dan data sekunder akan dianalisis secara kualitatif yaitu data yang diperoleh dikelompokkan dan diseleksi berdasarkan kualitas dan kebenarannya yang berkaitan dengan masalah yang diteliti. Hasil penelitian yang didapatkan akandipaparkan secara deskriptif, setelah bahan terkumpul kemudian dituangkan dalam bentuk uraian logis dan sistematis dan dihubungkan dengan dihubungkan dengan judul, latar belakang masalah, dan rumusan permasalahan. Penelitian ini dilakukan dengan cara membuat analisis sesuai dengan datadata primer dan sekunder yang didapat sehingga diharapkan mendapat hasil mengenai strategi pemasaran marketing mix pada program talk show Hitam Putih di Trans7.

\section{HASIL DAN PEMBAHASAN}

\section{Strategi Komunikasi Pemasaran Terpadu Produksi Program Talkshow Hitam Putih}

Komunikasi pemasaran terpadumerupakan konsep perencanaan komunikasi pemasaran yang menyadari nilai tambah dari suatu rencana komprehensif yang mengevaluasi peran strategis dari berbagai disiplin komunikasi, misalnya komunikasi umum, tanggapan langsung, promosi penjualan dan hubungan masyarakat (Kotler, 1997:228). Dengan kata lain, strategi komunikasi pemasaran terpadu memakai konsep komunikasi 
pemasaran terpadu menggabungkan berbagai aktivitas pemasaran secara bersamaan, yaitu pemasaran langsung (direct marketing), promosi penjualan (sales promotion), hubungan masyarakat (public relations), penjualan personal (personal selling), periklanan (advertising).Sesuai dengan tujuan penelitian ini, maka berdasarkan keterangan dari narasumber, yakni Mayang Widi Anjani yang saat ini menjabat sebagai Marketing Division Head Trans7, didapatkan hasil mengenai langkah-langkah strategi komunikasi pemasaran terpadu yang diterapkan oleh talkshow Hitam Putih, yaitu sebagai berikut :

\section{Pemasaran Langsung}

Melalui strategi komunikasi pemasaran langsung, perusahaan dapat melakukan diskusi kerjasama dengan konsumen atau calon pemasang iklan dalam dunia penyiaran. Terdapat banyak cara untuk melakukan komunikasi penjualan pribadi.Cara komunikasi yang dilakukan oleh divisi pemasaran program talkshow Hitam Putih adalah dengan bertatap muka langsung, melalui email, telepon, dan aplikasi chatting WhatsApp (keterangan Mayang Widi Anjani, Marketing Division Head Trans7). Bertemu secara langsung dan berkomunikasi lewat media telefon dengan calon pemasang iklan memungkinkan divisi pemasaran melakukan presentasi penjualan dengan lebih menarik dan lengkap dihadapan calon pemasang iklan dibanding berkomunikasi melalui media lainnya. Kelemahan media komunikasi dengan memakai email, dan aplikasi WhatsApp berupa respon yang diberikan tidak secara langsung oleh calon konsumen, sehingga divisi pemasaran harus lebih aktif untuk menanyakan terlebih dahulu mengenai penawaran slot iklan yang ditawarkan.

Pemasaran langsung yang dilakukan oleh tim pemasaran talkshow Hitam Putih menyasar para advertiser, media agency atau NBD (New Business Development) dan client-client baru yang belum pernah beriklan sebelumnya, misalnya dari institusi pemerintahan (penjelasan dari Mayang Widi Anjani, Marketing Division Head Trans7). Masing-masing sasaran ini mempunyai tujuan agar produk, jasa atau acara yang akan dibuat dapat populer dan diketahui oleh khalayak ramai sehingga meningkatkan penjualan. Para pihak yang menjadi sasaran pemasaran tentunya akan memperhatikan memperhatikan detail penawaran tayangan, untuk itu divisi pemasaran program harus mengetahui kelebihan dan kelemahan siaran iklan agar dapat menyusun strategi penjualannya dan meyakinkan para calon pemasang iklan.

Advetiser atau calon pemasang iklan membutuhkan ruang untuk mempromosikan produknya terus menerus. Media agency seperti media per-film-an tentunya akan senang bekerjasama dengan program talkshow untuk mempromosikan film-film mereka yang akan ditayangkan di bioskop dengan metode wawancara antara pembawa acara dan artist yang terlibat dalam film. New business development membutuhkan media penyiaran dengan rating dan share yang bagus untuk memperkenalkan produkproduk atau jasa baru buatan mereka. Serta pemerintah menggunakan media penyiaran sebagai upaya memberitahu acara atau agenda yang akan dilakukan oleh pemerintah dalam waktu tertentu. 
Sampai saat ini talkshow Hitam Putih telah berhasil bekerja sama dengan para sasaran calon pemasang iklan tanpa adanya hambatan (penjelasan dari Mayang Widi Anjani, Marketing Division Head Trans7). Talkshow Hitam Putih berhasil menyadari bahwa mendengarkan tanggapan langsung dari calon pemasang iklan (client) merupakan salah satu upaya penting dalam dunia pemasaran. Tanggapan langsung yang diberikan oleh client berfungsi sebagai umpan balik secara langsung dari produk yang ditawarkan sehingga efektif mengundang para calon pemasang iklan untuk membeli slot iklan atau mengadakan sponsorship serta menjaring lebih banyak calon penonton baru untuk menyaksikan program ini.

\section{Promosi Penjualan}

Berdasarkan keterangan dari Suci Mulya Putri,Public Relations Section Head program talkshow Hitam Putih memberikan promosi penjualan dalam bentuk souvenir/merchandisetalkshow Hitam Putih. Hal ini dapat dimengerti karena promosi penjualan yang dilakukan dengan memberi nilai tambah, seperti pemberian potongan harga, kupon, maupun sampel produk jarang dipakai apabila strategi pemasaran lain sudah berhasil dilakukan.Namun menerapkan strategi pemasaran promosi penjualan dapat menjadi nilai tambah bagi program talkshow Hitam Putih karena strategi ini, walaupun harus mengeluarkan intensif khusus, intensif ini juga berfungsi untuk merangsang reaksi langsung dari konsumen dan distributor, dalam hal ini calon pemasang iklan dan penonton. Reaksi langsung yang diberikan dapat menjadi masukan bagi perusahaan penyiaran serta peningkatkan kesadaran merek perusahaan.

\section{Penjualan Pribadi (personal selling)}

Menurut Mayang Widi Anjani selaku Marketing Division Head Trans7, divisi pemasaran program talkshow Hitam Putih menyadari pentingnya melakukan strategi penjualan pribadi. Divisi pemasaran melakukan komunikasi pemasaran pribadi dengan calon pemasang iklan dengan pendekatan personal needs clientsehingga akan didapatkan hasil kerjasama yang lebih spesifik. Komunikasi pemasaran penjualan pribadi melibatkan komunikasi dua arah antara pihak divisi pemasaran dengan calon pemasang iklan. Adanya komunikasi dua arah secara pribadi memudahkan divisi pemasaran menyampaikan keunggulan memasang iklan di program takshow Hitam Putih dengan detail dan calon pemasang iklan akan lebih puas bila ada pertanyaan atau permintaan yang dapat direspon dengan cepat sehingga terjadi umpan balik berupa transaksi penjualan.

Dalam melakukan komunikasi pemasaran penjualan pribadi kadang kala ditemukan hambatan-hambatan. Berdasarkan penjelasan dengan Mayang Widi Anjani, selama ini hambatan ditemukan adalah bagaimana menyesuaikan kebutuhan calon pemasang iklan dengan kebutuhan program talkshow Hitam Putih agar tetapsoft sell dan tidak mengganggu konten (blend in program).Selain hambatan dari calon pemasang iklan, diakui oleh Mayang Widi Anjani, hambatan lain datang dari bintang tamu atau narasumber yang diundang. Bintang tamu atau narasumber terkadang tidak dapat mengimbangi 
kritisnya pertanyaan dari pembawa acara karena tamu yang diundang oleh talkshow Hitam Putih datang dari berbagai latar belakang usia, pendidikan, keahlian dan masih banyak lagi. Namun, pembawa acara talkshow Hitam Putih menjadikan ini sebuah tantangan yang dieksekusi secara baik sehingga program tetap menarik untuk ditonton. Pembawa acara dituntut untuk luwesdalam memberi pertanyaan dan menanggapi jawaban dari bintang tamu, misalkan bintang tamu adalah seorang anak sekolah dasar (SD), maka pembawa acara akan memberikan pertanyaan secara ringan seperti berbicara dengan anak kecil.

\section{Hubungan Masyarakat (Public Relations)}

Berdasarkan keterangan dari Suci Mulya Putri, Public Relations Section Head Trans7, diketahui bahwa kegiatan public relations yang dilakukan oleh program talkshow Hitam Putih di Trans7 mencakup kegiatan menjaga hubungan baik dengan seluruh stakeholder perusahaan, memaksimalkan semua fungsi dalam public relations, dan memanfaatkan seluruh platform media. Segala kegiatan ini dilakukan oleh divisi public relations demi membina hubungan baik dengan berbagai kelompok masyarakat melalui publisitas yang mendukung, membina citra perusahaan yang baik dan menangani atau menangkal desas-desus, cerita, atau peristiwa yang dapat merugikan perusahaan.

Menjaga hubungan baik dengan seluruh stakeholder perusahaan merupakan poin penting dalam kegiatan membangun hubungan masyarakat. Stakeholder atau pemangku kepentingan suatu perusahaan dapat dikelompokkan menjadi dua, yakni stakeholder internal dan stakeholder eksternal. Stakeholder internal mencakup para pemegang saham, pemilik bisnis dan karyawan yang bekerja didalamnya. Sedangkan stakeholder eksternal terdiri dari masyarakat secara umum, lingkungan sekitar, media massa lainnya, maupun .

Perusahaan penyiaran dapat melakukan promosi secara lebih luas dengan bekerjasama dengan media massa lainnya. Namun, perusahaan pertelevisian cenderung memakai media cetak sebagai media promosi program-program tayangannya karena alasan persaingan. Sebagai contoh artikel yang dibuat oleh palembang.tribunnews.com, diterbitkan pada tanggal 21 Juli 2018 pukul 17:41 WIB yang berjudul "Deddy Corbuzier dibuat terharu saat program Hitam Putih sukses ubah hidup mantan atlet 'saya terharu'". Artikel ini memuat ungkapan rasa terharu Deddy Corbuzier sebagai presenter talkshow Hitam Putih mendengar nasib atlet sepeda yang pada masa tuanya menjadi tukang becak kini telah mendapat perhatian dari pemerintah Surabaya yang menjadikannya karyawan pemerintah kota dengan tugas melatih balap sepeda untuk anak jalanan. Muatan artikel ini mengandung nilai positif program talkshow Hitam Putih dan menimbulkan apresiasi bagi para pembacanya sehingga akan timbul rasa penasaran atas tayangan talkshow Hitam Putih di Trans7.

Masih berdasarkan keterangan dari Suci Mulya Putri, program talkshow Hitam Putih juga melakukan kerjasama CSR dengan pemerintah. Program ini dilakukan secara on air dengan menampilkan iklan layanan masyarakat selama program acara berlangsung. 


\section{Periklanan (Advertising )}

Bagi perusahaan penyiaran, selain iklan pada medianya sendiri, perlu dilakukan usaha lain untuk memasarkan program acaranya agar lebih banyak diketahui oleh masyarakat luas. Berdasarkan hasil wawancara dengan Public Relations Head Trans7, yakni Suci Mulya Putri, guna memasarkan program acara talkshow Hitam Putih, divisi marketing menggunakan media iklan lewat media sosial. Program acara talkshow Hitam Putih dipasarkan melalui akun media sosial official Trans7 dan Hitam Putih. Promosi program dilakukan sesuai tema/ episode yang akan disiarkan dan diposting di akun media sosial yang dapat diakses melalui website www.trans7.co.id/programs/hitam-putih,

instagram @officialtrans7 dan @officialhitamputihtrans7, twitter@trans7 dan @hitamputihT7, serta YouTube TRANS7 OFFICIAL. Sejauh ini promosi yang dilakukan lewat media sosial tersebut dirasa efektif karena hemat biaya dan dapat menjangkau banyak orang dari berbagai kalangan, usia, dan wilayah, mengingat pemakaian internet tidak terbatas ruang dan waktu.

\section{Strategi Pemasaran Media Online}

a. Content Marketing

Content Marketing memakai media website untuk memasarkan produk. Strateginya yakni menggunakan informasi dalam bentuk artikel, gambar, ataupun video yang berkaitan dengan penawaran produk yang dijual.

Menurut Suci Mulya Putri selaku Public Relations Head Trans7, program acara talkshow Hitam Putih memiliki website yang berisi informasi publik mengenai talkshow ini sendiri, yakni www.trans7.co.id/programs/hitam-putih. Selain informasi publik, website ini juga menyediakan video talkshow Hitam Putih yang telah selesai ditayangkan.

\section{b. Mobile Marketing}

Mobile marketing adalah strategi pemasaran online yang menyasar pada sasaran konsumen pengguna perangkat mobile atau handphone. Teknik ini memakai media SMS (short message service) dan email. Dari hasil wawancara dengan Mayang Widi Anjani yang menjabat sebagai Marketing Division Head Trans7, program acara talkshow Hitam Putih melalui tenaga pemasarannya mengirimkan penawaran memasang iklan selama program acara berlangsung dengan media email.

\section{c. Continuous Marketing}

Strategi pemasaran online ini memakai platform media sosial sebagai wadah promosinya. Media sosial yang digunakan diantaranya adalah Facebook, Twitter, dan Instagram. Sebagai wadah promosinya, program acara talkshow Hitam Putih mempunyai media sosialnya sendiri, yakni instagram @officialtrans7 dan @officialhitamputihtrans7, twitter@trans7 dan @ hitamputihT7 (Suci Mulya Putri, Public Relations Head Trans7).

\section{d. Integrated Digital Marketing}

.Media pemasaran dengan memakai semua media sosial yang ada, termasuk website.

Media sosial talkshow Hitam Putih sendiri telah memiliki pengikut yang banyak. Terhitung pada tanggal 13 Desember 2019 pukul 18.00 WIB, media instagram @officialhitamputihtrans7 
mempunyai 566 ribu pengikut, twitter @ @itamputihT7 6,1 juta pengikut dan facebook OfficialTRANS7 dengan 11.496 pengikut.

\section{e. Visual Marketing}

. Penampilan objek visual yang menarik dapat membuat sasaran konsumen penasaran dengan produk yang ditawarkan. Objek visual ini digambarkan dalam sebuah foto maupun video.

Penawaran program acara talkshow Hitam Putih dengan menggunakan media gambar dapat ditemui pada platform media sosial instagram, twitter, maupun facebook resminya yang telah penulis sebutkan diatas. Sedangkan video mengenai talkshow Hitam Puth biasanya ditayangkan melalui media sosial YouTube TRANS7 OFFICIAL yang sampai saat ini (13 Desember 2019 pukul 18.20 WIB) telah memiliki 11,3 juta pengikut dengan video yang telah diupload sejumlah 49 ribu video.

\section{f. Personalized Marketing}

Strategi pemasaran online jenis ini mengedepankan pelayanan terhadap konsumen secara pribadi atau personal. Setiap konsumen yang terjaring akan diperlakukan secara berbeda sesuai dengan hobi, minat, jenis kelamin, umur, serta perbedaan lokasi tempat tinggalnya, untuk itulah diperlukan suatu perangkat lunak khusus untuk mempelajarinya serta tim marketing riset yang mumpuni. Strategi ini sangat cocok diterapkan oleh e-comerce, namun dalam dunia penyiaran, strategi promosi online ini tidak begitu diminati karena lebih mengandalkan hasil rating dan sharring.

\section{DAFTAR PUSTAKA}

\section{Buku :}

Ardianto, Elvinaro, Dkk. (2009). Komunikasi Massa Suatu Penghantar. Bandung: Simbiosa Rekatama Media.

Branan, Tom. (1998). A Practical Guide To Intregated Marketing Communication. Alih bahasa : Sandiwan Suharto. Jakarta: PT Gramedia Pustaka Utama.

Departemen P dan K. (1989). Kamus Besar Bahasa Indonesia. Jakarta: Balai Pustaka.

Kennedy, John. R;R Dermawan Soemanagara. (2006). Marketing Communication Taktik dan Strategi. Jakarta: PT Buana Ilmu Populer.

Kotler, Philip. (1997). Manajemen Pemasaran Analisis Perencanaan, Implementasi dan Pengendalian (terjemahan Jaka Wasana). Jakarta: Salemba Empat.

Kotler dan Gary Armstrong. (1997). Dasar-dasar Pemasaran. Jakarta: Prenhallindo

Kotler dan Gary Armstrong, (1997). Prisip-prinsip Pemasaran. Jakarta: Erlangga.

Mahmud, Machfoedz. (2010). Komunikasi Pemasaran Modern. Yogyakarta: Cakra Ilmu,

Morissan,M.A. (2013). Manajemen Media Penyiaran, Strategi Mengelola Radio \& Televisi. Jakarta: Kencana Prenada Media Grup.

\section{Pemasaran Terpadu. Jakarta: Kencana.}

Morissan, Andy Corry Wardhani, Farid Hamid. (2009). Teori Komunikasi Massa. Bogor: Ghalia Indonesia.

Rakhmat, Jalaludin. (2004). Psikologi Komunikasi. Bandung: Rosdakarya.

Sulaksana, Uyung. (2007). Integrated Marketing Communication. Yogyakarta: Pustaka Belajar.

Sugiyono. (2007). Statistika Untuk Penelitian. Bandung: Alfabeta. 
Tuckwell, K. J. (2008). Integrated Marketing Communication: Strategic Planning Perspective. Second Edition. USA: Pearso Pretice Hall.

Wibowo, Fred. (2007). Teknik Produksi Program Televisi. Yogyakarta: Pinus Book Publiser.

\section{Jurnal :}

Masitah. (2014). Strategi Komunikasi Pemasaran Gajayana TV Dalam Mendapatkan Pengiklan Komersial. Kota Malang.

Ria Yunita. (2017). Strategi Komunikasi Pemasaran Dalam Mempertahankan Eksistensi Radio Dangdut Terdepan Di Jakarta (Studi Kasus Eksistensi Radio Cbb 105,4 Fm. Kota Jakarta Timur.

Siti Asiatun. (2018). Strategi Pemasaran Program Talkshow Mamah Dan Aa Beraksi Di Indosiar Dalam Peningkatan Rating Siaran. Sekolah Tinggi Multi Media Yogyakarta.

Website :

Noviyanto,https://koinworks.com/blog/macammacam-strategi-pemasaran-online/, diakses pada 13 Desember 2019 pukul 17.20 WIB.

www.id.wikipedia.org/wiki/Hitam_Putih_(acara_TV), diakses pada 08 Januari 2019 pukul 16.27 WIB.

www.trans7.co.id/programs/hitam-putih, diakses pada 08 Januari 2019 pukul 16.36 WIB.

www.trans7.co.id/about\#profile, diakses pada 17 Agustus 2019 pukul 10:19 WIB).

www.id.wikipedia.org/wiki/keterkaitan_ilmu_komunik asi_dengan_pemasaran), diakses pada 23 Mei 2019 pukul 11.33 WIB.

https://lifestyle.kompas.com/read/2013/05/31/1533295 3/Begini.Aturan.Iklan.Rokok.), diakses pada 21 Agustus 2018 pukul 12.33 WIB.

\section{Undang-Undang :}

Izin Penyelenggaraan Penyiaran Nomor 1820 Tahun 2016 tanggal 13 Oktober 2016.

Peraturan Menteri Kesehatan Nomor 28 Tahun 2013 